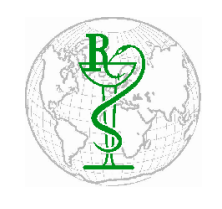

INDO GLOBAL JOURNAL OF

PHARMACEUTICAL SCIENCES

ISSN 2249- 1023

\title{
RNA Interference in Treatment of Diabetic Neuropathy
}

\author{
Shefali Goyal *, Shrishty Gupta *, Rachana \\ Department of Biotechnology, A-10, Jaypee Institute of Information Tech., Sec-62, Noida, India \\ Address for Correspondence: Shefali Goyal; goyalshefali26@gmail.com \& Shrishty Gupta; shrishtygupta92@ gmail.com
}

\begin{abstract}
According to WHO, 347 million people all over the world are diabetic. It is thought that, out of these 347 million people, $70 \%$ will develop some type of neuropathy over their lifetimes resulting in chronic pain. Chronic neuropathic pain (CNP) affects $21 \%$ of diabetic patients and is incurable. Current treatments for CNP focus on symptomatic relief which include the use of antidepressants and selective serotonin as first line agents. Opioid analgesics have been classified as second line agents. Third line agents, which include capsaicin (administered topically), have shown inconsistent results in the management of neuropathic pain and long term using of these agents have severe side effects. Present study focuses on using RNA interference to relieve CNP. In previous decades, various studies have been carried out and a large number of molecular targets for neuropathic pain have such as: TRPV1, P2X3, MMP2 and MMP9 and targets in dorsal root ganglion of the PNS, have been identified. These targets are also being explored to treat Diabetic neuropathy, as well. This review focuses on using RNAi as potential therapeutic technique to treat Diabetic neuropathy and associated pain. (C) 2014 iGlobal Research and Publishing Foundation. All rights reserved.
\end{abstract}

Conference Proceedings: International Conference on Life Sciences, Informatics, Food and Environment; August 29- 30, 2014

Indo Global Journal of Pharmaceutical Sciences( ISSN 22491023 ; CODEN- IGJPAI; NLM ID: 101610675) indexed and abstracted in EMBASE(Elsevier), SCIRUS(Elsevier),CABI, CAB Abstracts, Chemical Abstract Services(CAS), American Chemical Society(ACS), Index Copernicus, EBSCO, DOAJ, Google Scholar and many more. For further details, visit 